\title{
EMMANUEL LEVINAS: PARA UMA SOCIEDADE SEM TIRANIAS*
}

\author{
Rossana Rolando
}

Nós trabalhamos no presente não para o presente.

LÉON BLUM*

H á uma tese contida nas páginas de Levinas, já a partir do precioso texto de 1953, intitulado Liberdade e comando, tese que tem as próprias raízes em uma sofrida paixão civil, biograficamente amadurecida pela experiência novecentista do totalitarismo. Tal tese pode concentrarse toda na crítica a uma cultura - a 0 cidental -, cuja nobre aspiração à verdade acabou por traduzir-se, contra a sua vontade, em uma filosofia da potência geradora de violência e de tirania.

D uas vias correm paralelas, dois lados da mesma moeda: por um lado, a pretensão cognoscitiva que sempre animou a filosofia e a cultura ocidentais, delineando-se como redução ao eu de qualquer alteridade e individualidade, através da tomada conceitual; por outro lado, a tirania - como ação exercida sobre uma "massa inimiga" - cuja violência se aproxima da vontade de domínio com a qual o homem, por meio do trabaIho, serviliza para si as coisas. ${ }^{2}$ Se conhecer quer dizer tomar posse, dar forma, reconduzir ao uno, comandar significa "agir sobre uma vontade", ${ }_{3}$ ainda que violentamente, até manipular e aniquilar por meio da guerra.

* Publicado originalmente na revista La Società D egli Individui (Parma: Franco Angeli, 2001/2, ano IV, no 11) e traduzido do italiano por Fernanda L. O rtale e Ilse P. M oreira.

** Esta frase de Léon Blum, político francês e hebreu, aprisionado pelos alemães durante a segunda guerra mundial, é comentada por Levinas em U manesimo dell'altro uomo (H umanismo do outro homem), organizado por A. M oscato (Gênova: II M elangolo, 1998, p. 70), onde se lê, como explicação da passagem citada: “ $U$ m homem na prisão continua a acreditar em um futuro irrevelado e convida a trabalhar no presente para as coisas mais distantes, das quais o presente é irrecusável negação. [...] Agir pelas coisas distantes no momento em que triunfava o hitlerismo, nas horas surdas daquelas noites sem horas - independentemente de qualquer avaliação de 'forças em campo' - é, talvez, o sumo da nobreza". 
Como o sujeito do idealismo transcendental pretende, por meio do pensamento, englobar qualquer alteridade e reconduzir a si mesmo qualquer coisa que lhe é externa, realizando o ideal do 'conhecer igual a dominar', do mesmo modo, o tirano se comporta como se estivesse sozinho, considera o outro "na terceira pessoa", como uma "coisa" ou um caso particular de um todo. ${ }^{4}$ Para a tirania, não há o indivíduo, mas somente o geral, o anônimo, o oblíquo.

"A filosofia ocidental" não se "assegurou suficientemente" - diz Levinas - em relação à tirania, desta possibilidade inscrita na ontologia "do ser-para-reunir e para-dominar". ${ }^{5} \mathrm{~N}$ o entanto, é verdade que mesmo Platão era obcecado pelo espectro de tal possibilidade, tanto que deu vida ao grande afresco da cidade ideal que é, exatamente, A República platônica.

Como pode, portanto, não se repetir a experiência da tirania? Q ual é o calcanhar de Aquiles de uma filosofia cujo princípio foi sempre 0 da liberdade, seja na versão greco-platônica, seja na versão cristã-ocidental, analisada aguçadamente por Levinas em Algumas reflexões sobre a filosofia do hitlerismo? ${ }^{6}$

\section{0 logro da autonomia}

A tradição filosófica, com particular referência a Kant, mas também a Platão, como se estava dizendo, ensinou a liberdade entendida como recusa da imposição al heia, como autonomia, mesmo em relação ao que seja eventualmente comandado: "A vontade pode receber a ordem de uma outra vontade somente porque encontra essa ordem em si mesma". ${ }^{7}$

0 conceito kantiano de autonomia - com o qual se define a liberdade como autodeterminação da vontade - pressupõe uma razão comum a todos os homens, capazes de reconhecer o dever universalmente válido, porque inserido em tal razão, chamado com o nome de imperativo categórico. Kant contrapõe ao conceito de autonomia dar a si mesmo a própria lei, aquela que a razão indica, e ser por isso livre - o conceito de heteronomia, ou seja, o deixar-se determinar por algo exterior à razão: sentimento, impulso, mas também lei de um estado ou de uma igreja. ${ }^{8}$

Levinas retoma, com todo o respeito das coisas sérias, essa linha já platônica, segundo a qual podemos ser livres somente se aquilo que for comandado se apresentar como evidência ética para quem deve exe- 
cutar a ordem, como kantiana lei da razão: é a esta última que se obedece, e não à exterioridade do comando.

Portanto, sermos autônomos significa também recusar o comando irracional, arriscando-nos até mesmo à morte, se esse for o preço da liberdade. ${ }^{9}$ A morte de Sócrates é bela, ainda que injusta, talvez seja ainda mais bela exatamente porque injusta: ela atesta a possibilidade da recusa. ${ }^{10} 0$ tirano pode matar, mas não pode sujeitar a vontade, enquanto permanecer livre a reserva interior, a oposição do pensamento, a dimensão privada da consciência discordante.

"Todavia as coisas", adverte Levinas, "não são tão simples assim". ${ }^{11}$ Exatamente lá, de fato, no espaço interior, consuma-se "o logro" do alto conceito kantiano de autonomia. ${ }^{12} \mathrm{~A}$ tirania dispõe de meios - da tortura à intimidação, da propaganda ao pacto de silêncio, da ameaça à sedução - que podem demolir o poder de obedecer livremente, eliminando a própria consciência da tirania. ${ }^{13} 0$ homem, cuja liberdade é por natureza "não heróica", o homem feito de "medo e amor", acaba por aceitar a ordem do tirano como se viesse dele mesmo. ${ }^{14}$ Eis a obra mais terrível da violência: a obediência não é mais consciente, ela é, então, uma inclinação natural. ${ }^{15}$

0 que é minado ou obstruído, desde o início, é a própria capacidade de divergência, reserva dos espíritos livres, não reconhecida nos tempos obscuros da escravidão interior. Isso, de fato, revelou a experiência novecentista do totalitarismo: criou-se uma "índole de escravo", em que "o temor preenche a índole a tal ponto que não se enxerga mais, vê se tudo pela ótica do temor". ${ }^{16}$

\section{A ética hegeliana}

"O que permanece, todavia, livre" - diz Levinas - "é o poder de prever a própria renúncia e de "instituir fora de si uma ordem da razão": por meio de leis e instituições impedir que surja a tirania. ${ }^{17} \mathrm{~N}$ ão 0 imperativo categórico - visto que a 'pura' razão kantiana revelou-se uma abstração "sem defesas contra a tirania" -, mas uma lei externa, ou melhor, 0 direito. ${ }^{18}$ Este último, porém, embora nascido da livre vontade, não é por esta reconhecido: "as garantias tomadas contra a própria renúncia, a vontade as vive como uma outra tirania". ${ }^{19}$

Esse é um trecho implicitamente hegeliano: 0 direito, mesmo encarnando a racionalidade do querer, apresenta-se, uma vez escrito e sedimentado, como coerção, como lei estranha à "vontade viva que se 
renova a cada instante". ${ }^{20}$ Somente a moralidade pode satisfazer a distância e preencher o comando impessoal com a riqueza da intencionalidade. $^{21}$ D esse modo, $\mathrm{H}$ egel, unindo direito e moralidade no conceito de ética, considerou poder superar, com o direito, a abstração do imperativo categórico, conservando, porém, da moralidade kantiana, o comportamento interior, ou seja, a autoconsciência do bem intimamente e livremente assumido. ${ }^{22}$ Torna-se, assim, anulada a heteronomia inicial e no seu lugar encontra-se, enfim, uma mais 'concreta' e mais 'real' autonomia. ${ }^{23}$

Todavia, diz Levinas, "talvez seja impossível executar uma pura e simples identificação entre a vontade e a ordem da razão impessoal": a figura da ética hegeliana, de fato, apenas reflui à tendência totalitária, exaurindo-se a moralidade do indivíduo no interior do Estado, em que a Razão se encarna, e cuja vontade deve aderir. ${ }^{24} \mathrm{E}$ é, novamente, a síntese, a unidade que prevalece sobre a individualidade, e que não pode ter outro êxito se não a violência. $N$ ão é por acaso que 0 ideal hegeliano do Estado pode ser rastreado na polis grega, ${ }^{25}$ sob 0 signo da unidade, da harmonia, da totalidade acima da multiplicidade: sinal este - que já guiava a intenção platônica, voltada para construir uma cidade, na qual o justo não precisasse morrer e ser transformado, por uma espécie de trágica heterogênese dos fins, em protótipo de um estado do terror. ${ }^{26}$

Platão, por certo, tinha em mente o diálogo, o discurso como meio capaz de persuadir, de fazer entrar na situação de 'dentro da lei' sem exercer violência. Já no início de A República, antes de começar a tecer as argumentações da persuasão, Platão pergunta: "vocês teriam a força para convencer quem não quer escutar?", e a tradução de Levinas ressalta a contradição entre força, entendida como violência e persuasão. ${ }^{27}$

Convencer não é um atacar pelas costas, não é fazer emergir os sentimentos mais subterrâneos, como ocorre no engano retórico, que é uma forma sutil e perversa de violência. $\mathrm{N}$ ão é assim, convencer requer, previamente, o consentimento de quem quer escutar e quer entrar no discurso. ${ }^{28}$ Por isso, o perfil platônico de Trasimaco, que se sobressai no primeiro livro de A República, representa bem as diversas etapas do difícil trabal ho de persuasão: primeiramente ele recusa o diálogo e, ironicamente, considera o falar socrático no mesmo plano das fábulas contadas pelas velhas, na qual se responde sempre "bom" ou se fazem "gestos de sim e de não"; num segundo momento, porém, é ele mesmo - envolvido sem violência - a querer participar do discurso, discutindo com Sócrates. ${ }^{29}$ 
Como Platão, Levinas também pensa que se deva recomeçar a partir do discurso persuasivo e considera que seja necessária uma nova postura filosófica, capaz de fundar o respeito da lei na liberdade. ${ }^{30}$

\section{H eteronomia da ética}

O ra, o discurso de Levinas - aquele que deveria abrir percursos historicamente inusitados e do qual deveria nascer uma sociedade renovada, capaz de acertar as contas, mais uma vez, com a grande idéia da justiça -, dizíamos, começa a partir da ética, porque esta revira o princípio do domínio do eu. D efinir ética como a autêntica 'filosofia primeira' quer dizer, de fato, despir a ontologia, da qual sempre foi a depositária, colocando-se em uma perspectiva mais original. A ética é a porta para o exterior, a abertura em direção ao outro, à "ruptura da identidade". ${ }^{31} \dot{E}$ este o significado totalmente inédito do termo metafísica, fornecido por Levinas em polêmica com a tradição ocidental que, da transcendência, fizera um prolongamento do ser, ou melhor, do eu, dada a coincidência de saber e de ser na verdade. ${ }^{32}$

E exatamente a pretensão cognoscitiva do sujeito, a ontologia e, portanto, o espirito do sistema constituía para Levinas o correlativo da tirania ou da ação violenta. O ra, não pode ser o eu a despedaçar o sistema, como sustentava K ierkegaard, ${ }^{33}$ mas principalmente 0 outro, na medida em que é radicalmente não reconhecível, irredutível ao sujeito, não englobável em uma totalidade.

Antes de ser reconhecido, o outro se apresenta como vulto, essencialmente incompreensível. Levinas não pretende falar da incompreensão que deriva da preguiça ou da frieza com que passamos, indiferentes, um ao lado do outro, ${ }^{34}$ mas se coloca num plano mais original, aquém da compreensão ou da incompreensão: 0 da absoluta transcendência do outro, do oposto. 0 vulto não é uma 'coisa', por isso, não se pode fazer dele objeto de um tema e livrar-se, assim, da sua individualidade. Claro que podemos considerá-lo dentro de um conceito, ${ }^{35}$ mas não reduzi-lo a um conceito, eliminando dele a alteridade, obtendo daí uma derivação do eu: o outro é radicalmente 0 'não eu' e, neste sentido, é oposição. $A$ tirania consiste exatamente em recusar esta realidade oposta, em fazer existir somente o geral, o sem vulto.

A oposição implica, de fato, uma resistência. $\mathrm{N}$ ão porque o outro se apresente como força ou hostilidade: pode ser inerme, indefeso, nu, mas na sua nudez é resistência, enquanto oposição que não se dei- 
xa absorver, reconduzir à unidade. Trata-se de uma resistência ética e não física. ${ }^{36}$ Por isso, o tirano foge do face-a-face, da dimensão mais original que é a ética.

É o olhar do outro a impedir qualquer conquista: nele está inscrito o comando, o imperativo, a proibição do "não matar", ou melhor, de acordo com a importante especificação de Transcendência einteligi bilidade, 0 "fazer de tudo para que 0 outro viva". ${ }^{37} \mathrm{~A}$ implicação positiva do comando abre horizontes bem mais comprometedores do que a simples proibição do assassinato; ela nos adverte quão grande possa ser a gama dos modos em que se pode matar: e, então, matar é também mortificar a criatividade, a fantasia, a capacidade de amar e de sonhar, é isto e muito mais ainda.

A ótica, portanto, está completamente invertida: o comando vem do exterior, por isso Levinas nega a autonomia para insistir na radical heteronomia da ética. D ela deriva uma concepção diversa da liberdade: 0 outro não é o seu limite, mas a origem. Diante do vulto de outros, de fato, "o ingênuo direito dos meus poderes" se descobre arbitrário e injusto: é esta a consciência moral, o seu primeiro dado. ${ }^{38} 0$ outro não é uma ameaça para o meu arbítrio, mas é a medida da minha injustiça, daquilo que devia e podia fazer, do comando de que livremente me subtrai, da resposta que fora chamado a dar e que, voluntariamente, não dei.

Somente assim pode-se compreender porque a existência seja, para Levinas, "julgada e investida como liberdade", ao invés de sartrianamente "condenada à liberdade". ${ }^{39}$

Como no mito platônico do juízo final, os homens se encontram nus, despidos das suas roupas e das suas qualidades, para que nada contamine o juízo que sobre eles será expresso; mas para que cada um seja considerado somente com base naquilo que fez ou não fez, na justiça ou na injustiça do seu pensar querer operar. ${ }^{40}$ D o mesmo modo, na obra de Levinas, o outro está em si mesmo - fora de qualquer totalidade e antes de qualquer generalização - o Senhor, o M estre, o portador da ordem.

0 termo 'outro' (autrui), que obsessivamente retorna nas páginas de Levinas como 'cruz' para os tradutores, ${ }^{41}$ pode sugerir ao leitor uma reserva: não há, de fato, o outro cujo olhar, sartrianamente, oprime, o outro algoz, inquisidor, torturador, não somente em um plano histórico ou fatual, mas, mais comumente e não menos dramaticamente, no plano psicológico de relações subjugantes e despóticas? Também diante desse 'outro' somos responsáveis? 
Levinas não nega o princípio da "resistência ao mal", quando estiver em jogo não somente o destino pessoal, mas o destino coletivo, pelo qual devo também responder. ${ }^{42}$ É essa preocupação com todos os outros que coloca em campo a justiça e a defesa daquele que persegue o meu próximo, daí a necessidade da violência e do Estado. M as acrescenta: "se não houvesse ordem de Justiça, não haveria limite à minha responsabilidade"; mesmo se o vulto que tenho à frente fosse 0 do algoz, ele passaria diante de mim. ${ }^{43}$ Se permanecermos "na ordem do face-a-face", de fato valerá a admoestação de Dostoiévski, que Levinas não se cansa de repe tir: "nós somos todos culpados de tudo e de todos, e eu mais que todos os outros". ${ }^{44}$

O "para-o-outro", enquanto tarefa, anuncia-se, desde o princípio, não somente como abertura, diálogo, encontro com o tu, em termos buberianos, mas também, e principalmente, de acordo com as categorias fortes usadas por Levinas, como substituição, expiação, culpa. ${ }^{45}$ "Q uanto mais sou justo, mais sou culpado"; nisto consiste a unicidade do si mesmo: em "levar a culpa alheia", em ser acusado pelo que os outros fazem ou sofrem, como responsável por tudo, de acordo com o duplo significado do termo, tudo "me acusa", tudo "me diz respeito". ${ }^{46}$

Assim, a via que se abre diante do homem ético não é ladrilhada por promessas de uma vida feliz, mas, ao contrário, quanto mais se aperfeiçoa a consciência moral, mais parecem multiplicar-se os motivos de inquietude e de insônia pela miséria dos outros, e ainda fazem-se prováveis as possibilidades de sofrimento por causa dos outros, ou melhor, na lógica da responsabilidade, por outros. ${ }^{47}$ Lógica que chega até a expiação, não entendida como sobreposição de um resgate, magicamente tirado do sofrimento, mas considerada como passagem da humilhação sofrida na responsabilidade por quem a infligiu: nisto consiste 0 valor expiatório do sofrimento. ${ }^{48}$

\section{0 homem chega tarde ao mundo}

Se a responsabilidade de que fala Levinas não é um atributo da substância, mas é a própria substância, ou melhor, é o processo de "desubstancialização", "de-posição", "sujeição" do eu, então significa que 0 sujeito (subjectum) não possui em si o próprio princípio. ${ }^{49}$

0 homem, de fato, chegou "tarde em um mundo que não nasceu de seus projetos", de acordo com o belo texto Altrimenti che essere (Para além da essência), a obra levinasiana de maior êxito, sobretudo, se for 
lida à luz do quarto capítulo, que é o núcleo embasador de todo o livro. $^{50} \mathrm{~A}$ figura emblemática de tal homem é, exatamente, o bíblico Jó.

A história de Jó sempre suscitou muitas reflexões para os filósofos e não surpreende, portanto, que Levinas, não apenas por uma dívida cultural, se compare a este. ${ }^{51}$ Jó representa bem o dilema diante do qual se encontra a história do pensamento. Por um lado, ele resume todo 0 desejo de compreender, até colocar-se no lugar de Deus, erguendo-se em seu juízo, diante da enorme força do mal: é o caminho do 0 cidente, aquele que Levinas acredita que se deva deixar; por outro lado, porém, perante D eus que Ihe diz: "onde estavas quando criei a terra?", ${ }^{52}$ cala-se, muda de ótica sobre o mundo, reconhece que se encontra em uma lógica que não é sua.

A presunção dos filósofos idealistas - e assim se prossegue na comparação - consiste em raciocinar em nome da liberdade, como se fosse possível sermos responsáveis apenas por um mundo livremente desejado..$^{53}$ Essa também é a chave interpretativa com a qual se entra na página do famoso texto do Velho Testamento: Jó rebela-se diante do mal que não mereceu, declarando, em voz alta, a própria inocência; e assim os amigos, acudindo-o em seu leito de dor, repropõem, em defesa de D eus, a culpa de Jó, justificando, assim, o mal que pesa sobre ele. Ambos, porém, permanecem no interior do esquema culpa-pena, ambos pecam por presunção e por isso são, embora de maneiras diferentes, repreendidos por D eus. Eles, de fato, não consideram 0 atraso com 0 qual o homem entra no mundo, falam como se tivessem assistido ao projeto da criação, como se tal projeto devesse corresponder à própria lógica. M as "o 'atraso' não é insignificante" ${ }^{\prime 54}$ e isto é reconhecido por Jó em seu viril duelo com D eus.

A iniciativa, pois, não depende do homem, embora ao homem seja confiada a tarefa de "suportar o universo", de ser, portanto, responsável por um mundo não desejado por ele: "tarefa opressora" - lê-se, em letras cursivas, no texto de Levinas - "mas sofrimento divino", visto que provém de D eus. ${ }^{55}$

Como o protagonista de 0 Processo, de Kafka, posto sob acusação sem saber o porquê, o homem de Levinas é "acusado afora de sua culpa, antes da liberdade", sabe que querem algo dele sem ter, ele mesmo, desejado nada: deve responder por tudo como se fosse responsável por tudo, é perseguido sem qualquer possibilidade de defesa. ${ }^{56}$

Todavia, não é um mundo insensato que se projeta diante do homem ético, não é o absurdo de que fala a personagem kafkiana no meio de sua inconcebível prisão. Realmente, se não é o sujeito a origem 
do comando - visto que o primeiro dado da consciência é a exterioridade do dever - , também não será o sujeito a ser constituído como resposta a tal ordem, mas deveremos admitir um "antes" do ser, um ato criativo em que essa ordem teve origem. ${ }^{57} \mathrm{~N}$ ão se poderia, por isso, explicar a ética sem recorrer a um tempo anterior ao tempo, a "um passado imemorável" e "irrepresentável", a um 'outro lugar', ao qual pertence o Deus de Levinas: um $D$ eus que dá início ao mundo e se retira para sempre, entregando-o às mãos do homem, à sua única responsabilidade. ${ }^{58} \mathrm{D}$ esse $\mathrm{Ab}$ soluto - separado do mundo - o olhar do outro é sinal: une-se à idéia da criação não por causa de "uma tese ideológica", mas "partindo da experiência do vulto". ${ }^{59} \mathrm{~A}$ relação do homem "com 0 absolutamente ausente do qual provém não indica, não revela esse Ausente, todavia o Ausente tem um significado no vulto": o outro não manifesta Deus, mas remete a uma ordem absolutamente passada, que de D eus é o único vestígio". ${ }^{60}$

D esse desaparecer, no Silêncio, da Transcendência, subtraída de qualquer participação e posse, deriva um mundo adulto, sem Deus, ateu, e um homem plenamente habitante da terra, livre como é da nostal gia, da doença do retorno que, platonicamente, enfraqueceu 0 amor pela vida. ${ }^{61}$

Estamos, pois, muito distantes do "sermos jogados" de H eidegger: o conceito de criação, ou de uma ordem que precede o ser, é o contrário - afirma Levinas - da G eworfenheit heidggeriana. ${ }^{62} \mathrm{~N}$ ão se trata de aderir a um "ser-para-a-morte", mas a um sentido. ${ }^{63}$ Por isso, a questão fundamental não será a de ascendência leibniziana, do "por que o ser ao invés do nada" - por mais prometéica que pareça essa pergunta, novamente relacionada à pretensão cognoscitiva de um sujeito absoluto mas será ao contrário: "em que modo o ser se justifica" ou qual é o "meu direito de ser", como se eu devesse responder "antes de ter de ser". 64

Antes de responder em relação ao ser, ao agir, ao compreender, realiza-se, também no plano ético, a deposição do eu que constitui motivo inspirador da filosofia levinasiana. Até o momento em que a ética se fundará no princípio, mais ou menos mascarado, da expansão do ser, recairemos sempre na lógica de um sujeito que se coloca como início e fim do próprio agir e que, no outro, encontra o próprio limite: por isso, Levinas toma distância do primado do conotus essendi que espelha, em nível prático, a totalidade do sujeito transcendental em nível teórico. ${ }^{65}$

Sermos responsáveis, antes de ter de ser, significa, ao contrário, suspender a prioridade lógica e ontológica do eu, recomeçar dos outros para chegar a si ou, ainda, aderir a uma ordem originária para encontrar a própria identidade na resposta a este. ${ }^{66}$ Por um lado, de fato, a res- 
ponsabilidade é um destino antes de ser um ato de vontade: o homem é chamado para responder independentemente de qualquer decisão no plano ético; por outro lado, porém, a única possibilidade de encontrar um "sentido" no destino é a de aderir a este. ${ }^{67}$

Perante o comando do vulto podese decidir responder ou não, comprometer-se ou abster-se do compromisso, mas, nessa escolha, jogar-seá a própria liberdade, o ser ou o nada, o sentido ou o não sentido. ${ }^{68} \mathrm{Sim}$, porque, para Levinas, o eu vem depois do outro, constitui-se como resposta ao outro, como destinado ao outro. $\mathrm{N}$ ão foi ele quem escolheu esse modo de ser - 'para' e não simplesmente 'com' outros -, essa é a "orientação inevitável", mas é em corresponder-se ou não que realiza ou perde si mesmo. ${ }^{69}$

Por outro lado, não é apenas a perspectiva individual a ser evocada. Se D eus, de fato, retirou-se desde sempre e para sempre da história, e Ele é o D eus escondido, o Ausente, então quer dizer que desde o início Ele aceitou ser impotente em relação ao tempo - como chega a dizer $\mathrm{H}$ ans J onas em $\mathrm{O}$ conceito de $\mathrm{D}$ eus depois de Auschwitz - , confiando tudo ao agir e ao sofrer do homem ${ }^{70:}$ " $\mathrm{N}$ as dores daqui debaixo, o sofrimento do Altíssimo", e ainda, "Aquele que sofre no meu sofrimento - mesmo que seja o que eu mesmo mereci por causa do meu pecado - é Deus". ${ }^{71}$

Pode-se dizer, com Levinas, que exatamente nisto consiste a "kenosi" de Deus, o descender do infinito no finito, não no sentido hegeliano da coincidência dialética dos dois termos - dada a absoluta transcendência de Deus, que permanece tal no rebaixamento, sem entrar no mundo -, mas na forma do vulto que pede justiça: a "Palavra de D eus", de fato, "é a face al heia". ${ }^{72}$

Por isso, diante de "seis milhões de assassinados pelos nacionalsocialistas", assim como perante as "vítimas do mesmo ódio do outro homem", ${ }^{73}$ não é colocada em crise apenas a figura de D eus - com o fim da teodicéia tradicional -, é colocada em crise também a figura do homem, cuja ética não resistiu aos golpes da história. ${ }^{74}$

Eis porque, levinasianamente, não se deverá perguntar apenas 'onde estava D eus', quando a noite caía sobre a terra, mas, se não desapareceu qualquer sensibilidade moral; dever-se-á perguntar também e, sobretudo, 'onde estava o homem': “O problema que coloca a dor inútil, aparecida na sua maldade fundamental através dos acontecimentos do século XX, relaciona-se ao sentido que, depois do final da teodicéia, se podem ainda conservar a religiosidade, mas também a moralidade humana da bondade". ${ }^{75}$ 


\section{Liberdade ecomando}

É neste terreno doloroso, neste não poder e não querer esquecer, que se enráza vitalmente o problema da lei - contra 0 emergir dos monstros - e da obediência a esta na liberdade.

Retornamos, assim, ao início do nosso texto: a tirania, como foi dito, é o correspondente, no plano político, a um pensamento que colocou o eu como sujeito absoluto; apenas a filosofia da alteridade, enquanto ruptura da lógica do sujeito, poderá constituir a negação da tirania ou da ação que ignora o ol har do outro e, portanto, o comando. M as, para que isto se realize, é necessário encontrar uma mediação política no direito: não 0 imperativo categórico sem garantias contra o tirano, mas a lei impessoal que, para não ser vivida por sua vez como tirânica, e não ser, por outro lado, imposta com violência, pede para entrar em novo discurso, em um círculo.

A liberdade, não limitada pelo outro, mas nascida do outro, está no fundamento do direito: é da evocação do vulto, do entrar na sociedade, do facea-face que nasce o direito; e, vice-versa, o direito deve garantir o face-a-face, melhor dizendo, a liberdade contra atirania, a pluralidade, 0 encontro entre individualidades. ${ }^{76}$

O ra, a "possibilidade de entendimento entre os indivíduos", sob a ótica da instituição da lei, pressupõe, segundo Levinas, uma "razão" antes da "razão impessoal" ou do direito. ${ }^{77} \mathrm{M}$ as, então, devemos interrogar: não se recai assim no princípio da autonomia, aquele segundo o qual se pode aceitar o comando apenas se este encontrar confirmação na razão, havendo já, a priori, pressuposto? M as, exatamente a partir da exterioridade do comando - e, ressaltando toda a importância da questão na obra Totalidade e infinito: Ensaio sobre a exterioridade -, toma corpo a crítica do conceito de a priori.

$N$ ão éa função a ser negada, in toto, de a priori; aquela que é contestada é, ao contrário, a existência de um a priori capaz de perceber o fato de ser chamado, de ter de responder. ${ }^{78} \mathrm{Na}$ tradição socrático-platônica, nada pode vir de fora, mas tudo está, no fundo, já contido na alma: é essa a indicação da maiêutica socrática. ${ }^{79} \mathrm{Se}$, de fato - para dizer como Paul Ricoeur - "não fosse constituído responsável pelo meu dizer, sujeito da enunciação, sujeito responsável, capaz de manter as minhas promessas etc.; eu não poderia compreender aquilo queo outro exige equer de mim". ${ }^{80}$

Todavia, do ponto de vista de Levinas, isto quer dizer, novamente, retornar à filosofia da identidade, conduzindo o outro ao mesmo, 
fazendo um alter ego, uma 'reedição' de si: trata-se, ao contrário, de "deduzir" o plano epistemológico do plano ético ou o compreender do obedecer. ${ }^{81}$ Para Levinas, como se dizia, o imperativo não é uma lei que encontro em mim, mas algo que experimento no vulto do outro. É um comando inteligível, que certamente coloca em prática um caminho hermenêutico, feito também de pré-compreensões - a partir do momento em que o apelo dirigido a mim pelo outro requer uma contínua e cada vez mais profunda interpretação, se é verdade que a responsabilidade aumenta no momento em que nos tornamos eticamente mais exigentes com nós mesmos - mas, o comando não deriva de mim e as pré-compreensões que sugere são o resultado de uma vasta experiência ética. ${ }^{82}$

Q ue exista um a priori, em termos históricos, é prova o fato de que 0 direito pressupõe um entendimento, com base em uma experiência comum. Se não existisse já uma "relação de comando sem tirania", o que se experimenta na ética do vulto, não poderia nem existir a obediência a uma lei jurídica que imite a heteronomia da ética, deixando-se inspirar por esta e desta sendo a garantia. ${ }^{83}$

M as há um motivo posterior para reflexão, já presente, de forma embrionária, nas páginas finais de 0 tempo e 0 outro, de 1947 - escritas seis anos antes do ensaio Liberdade e comando - e desenvolvido de modo maduro a partir do texto de 1954, intitulado 0 eu e a totalidade, em que aparece a temática do "terceiro" ${ }^{84}$ Faço referência a esta, em momento de conclusão, para recapitular os pensamentos até aqui expostos.

A relação com o outro, para além da relação privilegiada que pode se instaurar entre os homens na forma de amizade, de entendimento, de eros, e que constitui a história privada dos afetos pessoais, apresenta-se, originalmente, como o apelo do estrangeiro, da viúva, do órfão, portanto, como exigência de toda a humanidade. " 85 "N os olhos que me olham" há toda a humanidade: é este 0 terceiro, 0 outro do outro que faz a sua aparição no vulto e "clama por justiça" ${ }^{86} \mathrm{~A}$ entrada em cena do terceiro, em relação direta com 0 outro, é um problema para a consciência. "O que devo fazer com justiça?" Como alcançar aqueles distantes que, na vizinhança do próximo, me obcecam? "O s outros, enfim, me dizem respeito": é este o último fruto da responsabilidade. ${ }^{87}$

A relação com o vulto enquanto próximo não é apenas o caminho que leva a todos os outros, mas é também o modelo a partir do qual se constroem e no qual encontram sentido as relações com todos os outros. ${ }^{88}$ A justiça, de fato, é impossível sem a proximidade: esta não se identifica 
com a legalidade, entendida como "técnica do equilíbrio social", mas pressupõe, para ser autêntica, a orientação de um para o outro. ${ }^{89}$

É claro que as instituições, a estrutura do Estado, a política, tendem, a cada momento, "a pesar por conta própria", a seguir leis próprias; e também - diz Levinas, colocando-se no lugar do profeta - estas não deverão nunca perder a ligação com a ótica da responsabilidade: sob pena de injustiça. ${ }^{90}$ Apenas se "não houver distinção entre vizinhos e distantes", se mantiver a assimetria da relação ética, se "a igualdade de todos é levada pela minha desigualdade", se houver, pois, um predomínio "dos meus deveres sobre os meus direitos", somente assim, "a justiça permanecerá como justiça". ${ }^{91}$

Eis a raiz ética da obediência ao direito: "o esquecimento de si mesmo move a justiça". ${ }^{92} \mathrm{~N}$ ão porque se deva, hegelianamente, adequar a uma Razão universal, que assume o conflito no interior do sistema, harmonizando a guerra original de todos contra todos, mas porque o Estado justo pode nascer apenas com base na preocupação "de um com todos". ${ }^{93}$

A única universalidade admitida por Levinas, a única racionalidade antes da razão impessoal ou do direito, é a responsabilidade. N esta, está presente também o eu, a ânsia pelo seu destino, integridade e "salvação": não diretamente, em relação ao querer individual, caprichoso e egoísta, mas em relação ao outro, a si mesmo, que é também outro para os outros, ao homem na sua totalidade. ${ }^{94}$

$E$, assim, é possível compreender como o movimento absolutamente passado, "anárquico" - não proveniente de mim - de um para o outro, seja a fonte de onde deriva, além da ética, a obediência ao direito, visto como meio indispensável para realizar a justiça em relação ao terceiro, àquele distante que apela ao próximo face-a-face: quase como se 0 terceiro fosse a humanidade, não apenas presente, mas também futura, cuja responsabilidade compromete-se a oferecer uma sociedade menos injusta, na qual seja possível viver em paz. ${ }^{95}$

Autorizado para publicação em agosto de 2001.

N otas

1. O ensaio Liberté et commandement foi publicado originalmente na Revue de métaphysique et de morale, LVIII, 1953, p. 264-272, tradução italiana Libertà e comando (Liberdade e comando), In: E. Levinas, A. Peperzak, Ética prima come filosofia (Ética primeiro como filosofia), organizado por F. Ciaramelli, M ilão: Guerini e Associados, 1993, p. 15-19. 
2. E. Levinas, Liberté et commandement, trad. it. cit., p. 22.

3. Ibidem, p. 17.

4. Ibidem, p. 23, 24.

5. Trata-se de uma referência a $\mathrm{H}$ eidegger, contida no Prefácio de 1990, que Levinas acrescentou por ocasião da tradução inglesa do texto Alcune riflessioni sulla filosofia del hitlerismo (Algumas Reflexões sobre a filosofia do hitlerismo), de 1934. A edição italiana deste texto também traz 0 Prefácio e é organizada por A. Cavalletti, Q uodlibet, M acerata, 1996, p. 21. Sobre a controversa ligação de Levinas com H eidegger pode-se consultar o diálogo Filosofia, Giustizia e Amore (Filosofia, justiça e amor), "aut-aut", 1985, 209-210, p. 14, 16 e a palestra 0 outro, utopia e justiça, in: Tra noi: Saggi sul pensare all'altro (Entre nós. Ensaios sobre a alteridade), organizada por E. Baccarini, M ilano: Jaka Book, 1998, p. 269-272, no qual Levinas expõe algumas considerações a propósito do conhecido livro de Victor Farias relativo a H eidegger.

6. Além do já citado Liberté et commandement, os textos de Levinas, sobre os quais se fará mais freqüentemente referência - para responder a tais perguntas - são os seguintes: La philosophie et l'idée de l'infini, apresentado na "Revue de métaphysyque et de morale", LXII, 1957, p. 241-253, trad. it. La filosofia e l'idea dell'infinito, in: E. Levinas, A. Peperzak, Etica come filosofia prima, cit., p. 31-46; Totalité et infini. Essai sur l'extériorité, Nijhoff, La H aye, 1961, trad. it. Totalità einfinito. Saggio sull'esteriorità, (Totalidadee Infinito: Ensaio sobrea exterioridade), M ilano: Jaca Book, 1980; Autrement qu'être ou au-delà de l'essense, Nijhoff, La H aye, 1974 trad. it. Altrimenti che essere (Para além da essência), M ilano: Jaca Book, 1995. Sobre o paralelismo entre tirania e filosofia ocidental, pode-se consultar Levinas, Totalité et infini, trad. it. cit., p. 44.

7. E. Levinas, Liberté et commandement, trad. it. cit., p. 16.

8. Assim, escreve nas primeiras linhas, o Teorema IV da kantiano Critica della ragione pratica (Critica da Razão Prática), trad. it. de F. Capra, Laterza, Bari, 1983, p. 42: "A autonomia da vontade é o único princípio de todas as leis morais e dos deveres que eles correspondem: ao contrário, toda heteronomia do livre arbítrio, não apenas não é a base de qualquer obrigação, mas é particularmente contrária ao princípio deste e à moralidade da vontade".

9. Cf. E. Levinas, Liberté et commandement, trad. it. cit., p. 16.

10. Ibidem, p. 17.

11. Ibidem, p. 16.

12. Ibidem, p. 18.

13. Ibidem, p. 17.

14. Ibidem, p. 18.

15. Ibidem, p. 17.

16. Ibidem, p. 17.

17. Ibidem, p. 18.

18. Ibidem, p. 19.

19. Ibidem, p. 20.

20. Ibidem, p. 19. Sobre a relevância da postura hegeliana - dentro do ensaio Liberté et commandement - filtrada através da leitura de Eric Weil, pode-se ver a nota do organizador italiano, trad. cit., na p. 19.

21. Cf. F. Rosenzweig, Hegel e lo Stato (Hegel e o Estado), Bologna: II Mulino, 1976, p. 362-363, onde é lucidamente argumentado "a essência fundamental da vontade de que se serve $\mathrm{H}$ egel para construir o Estado".

Educação \& Sociedade, ano XXII, no 76, 0 utubro/2001 
22. Cf. G.W. Hegel, Lineamenti di filosofia del diritto (D iretrizes da filosofia do direito), organizado por G. M arini, Bari: Laterza, 1987, p. 45 e 131.

23. Ibidem, p. 131.

24. E. Levinas, Liberté et commandement, trad. it. cit., p. 20, onde se lê ainda: "Com efeito, ninguém quer forçar os outros a aceitar a razão impessoal do texto, se não com a tirania ...". Para a redução operada pelo idealismo - de ética à política e dos indivíduos a simples "momentos em um sistema", cf. E. Levinas, Totalité et infini, trad. it. cit., p. 221 e 222.

25. Sobre este assunto, Italo $M$ ancini escreveu páginas muito bonitas, em Filosofia da praxis (Brescia: M orcelliana, 1986, p. 440-447), onde, pleno de citações, traz também à luz 0 relacionamento entre $\mathrm{H}$ egel e A República platônica.

26. É a nota critica popperiana ao Estado delineado por Platão e considerado, nas suas linhas programáticas, como "totalitário": K.R. Popper, La società aperta e i suoi nemici (A sociedade aberta e seus inimigos), vol I, Roma: Armando Editore, 1998, p. 117 e ss.

27. Platão, Rep. 327 d. Na tradução de F. Sartori (Bari: Laterza, 1984), a mesma passagem ficou assim: "Seriam algum dia capazes de persuadir, rebater quem não está escutando?".

28. Para a ligação entre discurso e violência, que se instaura na retórica, entendida como corrupção da vontade do outro, E. Levinas, Totalité et infini, trad. it. cit., p. 68-70.

29. Cf. Rep. 350 3, 351 c. A citação é comentada por Levinas, em Liberté et commandement, trad. it. cit., p. 21.

30. Ibidem, p. 20-21. Pode-se aplicar aqui, a Levinas, o que ele mesmo disse a propósito de $M$ artin Buber em Fuori dal Soggetto (Fora do Sujeito), organizado por F.P. Ciglia (G enova: $M$ arietti, 1992, p. 21): "O diálogo como Buber o concebe é anterior a essa universalidade do diálogo político. É um diálogo que faz, se posso me exprimir assim, 'entrar no diálogo'. É aquilo que Platão procurava sempre: se você fala comigo eu posso convencer-Ihe, mas como obrigá-lo a entrar no diálogo? Buber procura o diálogo que faz entrar no diálogo".

31. E. Levinas, Autrement qu'être ou au-delà de l'essence, trad. it. cit., p. 19.

32. Idem, Liberté et commandement, trad. it. cit., p. 26, onde se lê: "a relação metafísica, a relação com o exterior, é possível somente como relação ética". Com o tema da correlação entre saber e ser abre-se o ensaio Ética primeiro como filosofia, contido no texto homônimo, cit., p. 47.

33. Idem, Totalité et infini, trad. it. cit., p. 38.

34. Idem, La philosophie et l'idée de l'infini, trad. it. cit., p. 45.

35. Idem, Totalité et infini, trad. it. cit., p. 218.

36. Idem, Liberté et commandement, trad. it. cit., p. 22-23. Pode-se ver ainda: La philosophie et l'idée de l'infini, trad. it. cit., p. 40.

37. Idem, Trascendenza e intelligibilità (Transcêndência e intelegibilidade), organizado por $F$. Camera (G enova: M arietti, 1990, p. 37). D a proibição inscrita no olhar do outro fala-se em La philosophie et l'idée de l'infini, trad. it. cit., p. 40.

38. Idem, La philosophie et l'idée de l'infini, trad. it. cit., p. 43-44.

40. Platão, Gorgia, 523a-e, 524a, comentado por Levinas na nota da p. 200 do já citado Autrement qu'être ou au-delà de l'essence.

41. A especificidade do termo autrui, na linguagem de Levinas, é sublinhada por Francesco Paolo Ciglia, organizador de N omes próprios, M arietti, Casale M onferrato, 1984, nas p. 191-192 e nas notas de Alberto M oscato, em H umanismo do outro homem, cit. p. 25-26.

42. Cf. Filosofia, justiça e amor, em "aut-aut", cit. 4-5. 
43. Ibidem, p. 5 .

44. Ibidem.

45. E. Levinas, Autrement qu'être ou au-delà de l'essence, trad. it. cit., p.116. Para a crítica ao "tu" de Buber, que pressupõe a reciprocidade, transpondo assim a originária assimetria do relacionamento ético, Id., veja-se Totalité et infini, trad. it. cit., p. 67 e, para um tratado mais articulado, Id., N omi propri, cit., p. 40-43 ou, ainda, Id., Fuori dal soggetto (Fora do sujeito), cit., p. 4349.

46. Idem, Autrement qu'être ou au-delà de l'essence, trad. it. cit., p. 141, 140, 145.

47. Ibidem, p. 116 e 139.

48. Ibidem, p. 139.

49. Ibidem, p. 145, 146, 160.

50. Ibidem, p. 154. A importância do quarto capítulo é marcada pelo organizador italiano de Autrement qu'être ou au-delà de l'essence, trad. it. cit., em nota preliminar na p. 2 e, mais detalhadamente, nas p. 124-125.

51. Ibidem, p. 154.

52. Assim, Levinas traduz o versículo 4, capítulo 38 do livro de Jó, em Di Dio Che viene all'idea (De D eus vem a idéia), sob os cuidados de S. Petrosino, M ilão: Jaca Book, 1986, p. 160.

53. Cf. Levinas, Autrement qu'être ou au-delà de l'essence, trad. it. cit., p. 154.

54. Ibidem, p. 154

55. Ibidem.

56. I bidem, p. 153. Cf. também Ibidem, p. 157, 145, 153. A relação entre Kafka e o pensamento bíblico é considerado por André N eher em Chiavi per I'ebraismo (Interpretações para 0 hebraísmo), Genova: M arietti, 1988, p. 105. É ainda importante para a assonância observada o fato de Kafka ter sido um dos autores de Blanchot, a quem Levinas era ligado por uma profunda afinidade intelectual edequem escreveno ensaio Blanchot/L osguardo del poeta (Blanchot/ 0 olhar do poeta), "aut-aut", cit., p. 131, 134.

57. Cf. E. Levinas, Autrement qu'être ou al-delà de l'essence, trad. it. cit., p. 148, 152.

58. Ibidem, p. 110, 154

59. E. Levinas, Liberté et commandement, trad. it. cit., p. 27.

60. Idem, Scoprire lésistenza com H usserl e H aidgger (D escobrir a exi stência com H usserl e H eidegger), trad. it. de F. Sossi, M ilão: Raffaello Cortina Editore, 1998, p. 227. Sobre o tema do "sinal/ vestígio" recorrente nas páginas de Levinas, pode-se ver: I bidem, p. 232-233; Id., Totalité et infini, trad. it. cit., p. 77; Id., Autrement qu'être ou au-delà de I'essence, trad. it. cit., p. 16-17, 116, 147 e, ainda, Id., H umanismo do outro homem, cit., p. 95-99.

61. Idem, Totalité et infini, trad. it. cit., p. 31-32, 39, 103 e, sobre a importante crítica ao conceito de "participação", p. 56-57, 106.

62. Idem, Liberté et commandement, trad. it. cit., p. 27.

63. Idem, Autrement qu'être ou au-delà de l'essence, trad. it. cit., p. 162.

64. Idem, Ética primeiro como filosofia, In: Levinas \& Paperzak, Ética primeiro como filosofia, cit,, p. 59 e 56 .

65. Idem, Autrement qu'être ou au-delà de l'essence, trad. it. cit., p. 160. 0 tema da contraposição entre conatus essendi e responsabilidade aparece também - e é um verdadeiro Leitmotiv na reflexão de Levinas - no texto filosoficamente mais importante da produção sucessiva a Autrement qu'être ou au-delà de l'essence (1974), vale dizer, em D e D eus que vem a idéa, cit., p. 179-180. 
66. Idem, Ética primeiro como filosofia, contido no texto homônimo, cit., p. 58.

67. Assim, de fato, lê-se em Autrement qu'être ou dau-delà de l'essence, trad. it. cit., p. 187: "a percepção da ordem coincide com a significação dessa ordem instituída por aquele que obedece." Cf. também p. 163, 188. Sobre o "sentido" do vulto antecedente a qualquer "atribuição a sentido", Id., Liberte et commandement, trad. it. cit., p. 26-27.

68. E. Levinas, Totalité et infini, trad. it. cit., p. 224.

69. Ibidem, p. 220. Sobre a crítica ao "ser com" de Hiedegger, cf. E. Levinas, Filosofia, justiça e amor, aut-aut, cit., p. 14.

70. H. Jonas, 0 conceito de $D$ eus depois de Auschwitz, G enova: M elangolo, 1993, p. 34 ess. 0 tema da "impotência" de D eus, na sua ligação com o conceito levinasiano de criação, é tratado por C armine Di Sante no ensaio 0 silêncio de D eus em Auschwitz, contido em Jó, o problema do mal no pensamento contemporâneo, Assisi: Cittadella, 1996, p. 86-88. Sobre o "sentido ético" da criação, entendido como renúncia do Criador "para deixar um lugar ao ser separado", escreveu Silvano Petrosino, em Fundamento e exasperação. Saggio sul pensare de Emmanuel Levinas (Ensaio sobre o pensamento de Emmanuel Levinas), G enova: M arietti, 1992, p. 138.

71. E. Levinas, Transcendência e intelegibilidade, cit., p. 51.

72. Ibidem, p. 49, 51, 47. Sobre a distância da dialética hegeliana, ibidem, p. 46, 53.

73. Assim afirma a dedicatória específica a Autrement qu'être ou au-delà de l'essence, trad. it. cit..

74. Sobre a crítica de Levinas à teodicéia tradicional, é iluminante o parágrafo do título "o fim da teodicéia", contido em Tra noi (Entre nós), trad. it. cit., p. 130-134, onde se lê: "A palavra de $\mathrm{N}$ ietzsche sobre a morte de D eus não ganhava força nos campos de extermínio, o significado de um fato quase empírico?" (p. 130). Sobre o rastro de N ietzsche e naturalmente de Kant, cujo ensaio Sobre o insucesso de toda tentativa filosófica em teodicéia - editado em italiano pela editora M arietti e contido em Q uestões de fronteira, Genova, 1990 - constitui uma pedra milenar da especulação filosófica, Levinas coloca-se ao lado de outros pensadores do campo hebraico: das reflexões de Jonas, ou ainda da aflita produção literária de W iesel. Sobre esse último autor, vide, especificamente, 0 apólogo narrado no livro A noite, Florença: Giuntina, 1980, p. 65-67.

75. E. Levinas, "O sofrimento inútil", In: Entre nós, trad. it. cit., p. 132. A sensibilidade em relação ao "direito do outro", quando todos os valores parecem desaparecer, é notada por Levinas na sua discussão com S. M alka, relatado no final do já citado Ler Levinas, p. 122-123.

76. Idem, Liberté et commandament, trad. it. cit., p. 21, 25, 18.

77. Ibidem, p. 20-21.

78. Cf. E. Levinas, Autrement qu'être ou au-delà de l'essence, trad. it. cit., p. 107, 108, 110, 125. Pode-se consultar também, La philosophie et l'idée de l'infini, trad. it. cit., p. 45.

79. Idem, Totalité et infini, trad. it. cit., p. 41.

80. A existência de um a priori como condição para entrar em relação com o outro é um dos pontos de divergência entre Ricouer e Levinas, conforme emerge do diálogo entre os dois filósofos relatado em E. Levinas, G. M arcel \& P. Ricoeur, II pensiero dell'altro (0 pensamento do outro), organizado por F. Riva, Roma: Lavoro, 1999, p. 73 e ss.

81. Ibidem, p. 75.

82. Cf. E. Levinas, La philosphie et l'idee de l'infini, trad. it. cit., p. 44. A fundação da compreensão de outros, a partir do comando do vulto, é explicitada em D i D io che viene all'idea, trad. it. cit., p. 122-123. Enfim, sobre a derivação do plano psicológico a partir do plano ético, vide: Autrement qu'être ou au-delà de l'essence, trad. it. cit., p. 183, onde "a substituição" é considerada como a condição "que torna possível as paradoxais possibilidades psicológicas do colocarse-no-lugar-de-um-outro". 
83. Idem, Liberte et commandement, trad. it. cit., p. 21. Pode-se consultar também Totalité et infini, trad. it. cit., p. 309, e Autrement qu'être ou au-delà de l'essence, trad. it. cit., p. 198, 200, 201.

84. Sobre o ensaio 0 eu e a totalidade, remete-se à tradução italiana de E. Baccarini, em Entre nós, trad. it. cit., p. 46 e ss., enquanto 0 tempo e o outro está disponível na edição italiana organizada por Francesco Paolo Ciglia, Genova: M elangolo, 1997 (no texto se faz referência à p. 53). A problemática do "terceiro" permanecerá uma constante nas reflexões de Levinas, mesmo nas obras principais, de Totalité et infini a Autrement qu'être ou au-delà de I'essence, a que faremos referência.

85. Cf. E. Levinas, Totalité et infini, trad. it. cit., p. 217, 218, 220.

86. Ibidem, p. 218, 220.

87. E. Levinas, Autrement qu'être ou au-delà de l'essence, trad. it. cit., p. 197, 198.

88. Ibidem, p. 199.

89. Ibidem, p. 199.

90. Ibidem.

91. Ibidem. Pode-se consultar também Levinas, Totalité et infini, trad. it. cit., p. 221.

92. E. Levinas, Autrement qu'être ou au-delà de l'essence, trad. it. cit., p. 199.

93. Ibidem.

94. Ibidem, p. 201. Q uanto à ligação entre "salvação" e "vida cotidiana" - não concebida como "traição em relação ao nosso destino metafísico", mas como primeira expressão de liberdade: a de "prazer" daquilo que é necessário para viver, são dedicadas as p. 31-35 de 0 tempo e o outro, o texto de 1947 supracitado. Elas antecipam a ampla discussão do sucessivo texto Totalité et infini (1961), trad. it. cit., p. 123 e ss.

95. A responsabilidade foi considerada por Levinas como "a racionalidade da paz", In: Autrement qu'être ou au-delà de l'essence, trad. it. cit., p. 200. Sobre o tema da paz trata Jacques D errida em Adeus a Emmanuel Levinas, organizado por S. Petrosino, M ilão: Jaca Book, 1998, p. 153 e ss. Com relação ao termo "anarquia", vide as p. 126, 201, 202 do supracitado Autrement qu'être ou au-delà de l'essence. 